\title{
STRENGTHENING AND MECHANICAL STABILITY MECHANISMS IN
}

\section{NANOSTRUCTURED BAINITE}

Behzad Avishan $^{\mathrm{a}}$, Carlos Garcia-Mateo ${ }^{\mathrm{b}}$, Lucia Morales-Rivas ${ }^{\mathrm{b}}$, Sasan Yazdani ${ }^{\mathrm{a}}$, Francisca G. Caballero ${ }^{\mathrm{b}}$

${ }^{a}$ Faculty of Materials Engineering, Sahand University of Technology, Tabriz, Iran

${ }^{b}$ MATERALIA Research Group, Department of Physical Metallurgy, Centro Nacional de Investigaciones Metalurgicas (CENIM-CSIC), Avda. Gregorio del Amo, 8. E 28040 Madrid, Spain.

Corresponding Author: Dr. Carlos Garcia-Mateo.

Affiliation: CENIM-CSIC

Address: Avda. Gregorio del Amo, 8. Madrid Spain

Tf: +34 915538900 ext 364

E-mail: $\underline{\text { cgm@ } @ \text { cenim.csic.es }}$

\section{ABSTRACT}

Understanding the main relationships between the microstructure parameters controlling the strength and ductility of low temperature bainitic microstructures is of considerable importance for further development of these grades. Although the microstructure essentially consists of solely two phases, bainitic ferrite and retained austenite, the complexity of the different microstructural characteristics, natural consequence of its unique transformation mechanisms, might not provide with one unique answer but a set of several parameters interdependent among them. This paper will deal with some of these relationships microstructure-properties, strength and ductility, with special emphasis in the mechanical stability (TRIP effect) of retained austenite.

Keywords: bainite, TRIP, mechanical stability, strength 1 


\section{INTRODUCTION}

Almost routinely, today it is possible to design alloys which give rise to a nanostructured bainite by isothermal transformation at low temperatures $\left(125-325^{\circ} \mathrm{C}\right)$. The development process is relatively simple and it implies the use of detailed phase transformation theory and some metallurgical facts [1-5]. The microstructure consists of a matrix of ultra fine bainitic ferrite plates (30-40nm) and a dispersed second phase, retained austenite. Retained austenite exhibits two very distinguishable morphologies, as thin films between the plates of ferrite, also in the nano range, and as blocks separating sheaves of bainite (groups of bainitic ferrite plates sharing a common crystallographic orientation). This mixed microstructure, with a strong composite character, presents an excellent balance of mechanical properties [6,7]. Due to the absence of fine carbides, the steels have a high resistance to cleavage fracture and void formation. Regarding the strength, the main contribution mainly comes from the substructure of the ferritic matrix, i.e. high fraction of slender plates of bainitic ferrite. On the other hand, it is believed that ductility in these microstructures is controlled by the amount and nature of retained austenite [7-10], which is a ductile phase when compared with bainitic ferrite. As further improvement of ductility can be achieved by transformation to martensite, TRIP effect, retained austenite mechanical stability (or its capability to transform to martensite under strain or stress) must be controlled and understood.

In this work, an attempt is made to review and depict some of the most important relationships between different microstructural parameters and the strength and ductility of the final microstructure in a new set of nanostructured bainitic steels. Special attention will be paid to the effect that the chemical composition, morphology-size-distribution and strength of austenite have on its mechanical stability, therefore in the evolution of the TRIP effect as a function of the applied strain. 


\section{MATERIAL AND EXPERIMENTAL PROCEDURE}

The chemical composition of the alloys used in this study are listed in Table 1, and it is the result of theoretical design by means of phase transformation theory alone [11], in order to obtain carbide free bainitic microstructures after isothermal heat treatment at low temperature. Further details on the steps followed to design such type of alloys are given elsewhere [3-5]. Suffice to say that both alloys were designed to have almost identical To curves and bainitic region in TTT diagrams [12]. A high C content ensures low bainite and martensite start temperature, $\mathrm{B}_{\mathrm{S}}$ and $\mathrm{M}_{\mathrm{S}}$, while 1.5 wt.\% $\mathrm{Si}$ inhibits the precipitation of cementite [11]. Elements as $\mathrm{Co}$ and $\mathrm{Al}$ have an accelerating effect on bainitic transformation [13], Mo avoids temper embritlement due to $\mathrm{P}$ and $\mathrm{Mn}, \mathrm{Cr}$ and $\mathrm{Ni}$ are used for hardenability purposes. In the case of Steel 2 the Mn content was reduced by almost $1 \mathrm{wt} . \%$ and its effect on the $\mathrm{T}_{0}$ curve as well as on the TTT diagram needed to be compensated by a substantial increase in the $\mathrm{Ni}$ content, 2.6wt.\%. Small quantities of $\mathrm{V}$ were added in Steel 2 to restrict prior austenite grain size (PAGS) growth during the austenitising heat treatment by pinning grain boundaries with $\mathrm{V}(\mathrm{CN})$.

Both alloys were cast in an induction furnace under inert Ar atmosphere and were electro slag remelted to gain clean steels free of inclusions. After being homogenized at $1200^{\circ} \mathrm{C}$ for $2 \mathrm{~h}$, they were hot rolled at a temperature of about $950^{\circ} \mathrm{C}$. Finally, lumps of $5 \times 5 \times 10 \mathrm{~mm}^{3}$ were cut and prepared for heat treatments. By means of high resolution dilatometry the $\mathrm{Ac}_{3}$ temperature of both alloys was determined to be $\approx 845^{\circ} \mathrm{C}$, therefore austenitization was performed at $900^{\circ} \mathrm{C}$ for $30 \mathrm{~min}$. in a salt bath. Samples were then immediately transferred to another salt bath at $200^{\circ} \mathrm{C}$, a temperature between the theoretically determined Ms and Bs temperatures, 80 and $290^{\circ} \mathrm{C}$ respectively, where samples were held for 3 days, time needed to ensure the end of bainitic transformation.

Prior austenite grain size was evaluated after applying the austenitisation conditions, following the thermal etching technique procedures described in refs. 14,15 . 
To reveal the microstructure, metallographic samples were cut, ground and polished following the

standard procedures. A $2 \%$ Nital etching solution was used to reveal bainitic microstructure. Scanning electron microscopy observation was carried out on a FEG-SEM HITACHI S-4800 field emission gun scanning electron microscope (SEM-FEG) operating at $7 \mathrm{kV}$. Before etching, samples were polished using colloidal silica suspension. High magnification SEM-FEG micrographs were used to determine the distribution and size of the different microstructural features analyzed.

TEM specimens were sliced from 3-mm-diameter rods of the heat-treated material, mechanically thinned to $0.06 \mathrm{~mm}$, and then twin-jet electropolished to perforation using a mixture of $5 \%$ perchloric acid, $25 \%$ glycerol and $70 \%$ ethanol at $10{ }^{\circ} \mathrm{C}$ at $45 \mathrm{~V}$. The samples were examined on a TEM JEOL 2100 transmission electron microscope operated at $200 \mathrm{keV}$.

Quantitative X-ray diffraction analysis was used to determine the fraction of retained austenite $\left(\mathrm{V}_{\gamma}\right)$ and its carbon content $\left(\mathrm{C}_{\gamma}\right)$. For this purpose, samples were machined, ground and finally polished using $1 \mu \mathrm{m}$ diamond paste, samples were then subjected to several cycles of etching and polishing to obtain an undeformed surface and finally were finished in colloidal silica. They were then step-scanned in a Brucker-Axs D8 X-ray diffractometer using unfiltered Co K $\alpha$ radiation. The scanning speed (2 $\theta$ ) was less than 0.3 degree/min. The machine was operated at $40 \mathrm{kV}$ and $30 \mathrm{~mA}$. The volume fraction of retained austenite was calculated from the integrated intensities of (111), (200), (220) and (311) austenite peaks, and those of (110), (200) and (211) planes of ferrite, using this number of peaks avoids possible bias due to crystallographic texture [16]. Moreover, retained austenite composition was calculated making use of the relationship between lattice parameter and chemical composition as reported in ref. [17], and assuming that during transformation only carbon diffuses [11]. Thus, the concentration ratios of all elements but $\mathrm{C}$ should be equal in the bulk material as in the retained austenite $(\gamma)$; in other words, $\left(\mathrm{x}_{\mathrm{Fe}} /\right.$ $\left.\mathrm{x}_{\mathrm{j}}\right)_{\text {bulk }}=\left(\mathrm{x}_{\mathrm{Fe}} / \mathrm{x}_{\mathrm{j}}\right)_{\gamma}$, where $\mathrm{j}$ denotes any substitutional element in the alloy, and $\mathrm{x}_{\mathrm{Fe}} \mathrm{y} \mathrm{x}_{\mathrm{j}}$ are the concentrations of $\mathrm{Fe}$ and of the substitutional elements, respectively [7,18]. The X-ray data from the 4 
underformed microstructure was also analyzed for non-uniform strains, i.e. peak profile broadening,

which is directly related to the dislocation density [19].

Tensile tests were performed at room temperature in specimens with a section of $2.9 \times 1.4 \mathrm{~mm}^{2}$ and a gauge length of $10 \mathrm{~mm}$. All experiments were assisted by an extensometer fitted to electronic equipment that allowed the continuous tracking of load-displacement data during tests. Load and elongations measured during uniaxial tensile tests were converted to engineering and true stress-strain curves. Strain hardening was characterized by the incremental strain-hardening exponent $n=d(\ln \sigma) / d(\ln \varepsilon)$ obtained from the true stress-true plastic strain curve.

Hardness was measured as $\mathrm{HV}(30 \mathrm{~kg})$ and the presented results correspond to an average of at least 3 values. Finally, all the necessary thermodynamic calculations were performed by means of MTDATA with the NPL-plus data base for steels [20].

\section{RESULTS AND DISCUSSION}

\section{Microstructural characterization.}

Experimental quantitative data presented in Table 2 shows that, as expected, the microstructure consists of a mixture of two phases, a dominant phase, bainitic ferrite $(\alpha)$, with fractions of 0.58 and 0.67 in Steel 1 and Steel 2 respectively, and carbon enriched regions of retained austenite $(\gamma)$. Bainitic ferrite in Figure 1 (a) and (b) is present as feather like features called sheaves, which consists of aggregates of plates (or sub-units) sharing a common crystallographic orientation, see darker features in Figure 1 (c) and (d). When referring to retained austenite morphology, it is necessary to distinguish between the blocky morphology, bounded by crystallographic variants of bainite sheaves and exhibiting polygonal shape in two dimensional sections, dark blocky features in Figure 1 (a) and (b), and the thin films of austenite found between the subunits within a given sheaf of bainite, see the interwoven lighter phase in Figure 1 (c) and (d). Extensive TEM observation failed to reveal any cementite, as it is expected from adding 5 
1.5wt.\% Si [11], see micrographs in Figure 2. Bainitic ferrite plates show the well known rational

Kurdjumov-Sachs (K-S) orientation relationship with the parent austenite in which it growths $[11,21,22]$, as illustrated in Figure 2 where the corresponding Selected Area Diffraction (SAD) patterns, presenting the K-S crystallographic relationship, with $\{111\} \gamma / /\{110\} \alpha$ and $<110>\gamma / /<111>\alpha$, between bainitic ferrite and austenite. TEM micrographs also revealed intense dislocation debris, due to the plastic relaxation of the shape change occurring as a consequence of the displacive growth of bainite. The plastic relaxation commonly takes place via generation of both, dislocations in the austenite/bainitic ferrite interface, and also via micro/nano twins in the austenite in contact with bainitic ferrite plates [23-25]. As the transformation temperature decreases, the combination of local increase in dislocation density caused by the yielding of the austenite together with the increase of the strength of austenite itself, are found to be the two main factors controlling the scale of the microstructure, both factors increasing in intensity as transformation temperature is lowered [26,27]. Both grades were conceive under those premises, and bainitic ferrite plate thickness in Table 2 come to corroborate the benefits of low transformation temperatures on the scale of the final microstructure, with thicknesses within the nano-range, 39 and 35 nm for Steel 1 and 2 respectively, and a distribution, Figure 3, that does not show noticeable differences between both alloys. Slenderness is not exclusive of bainitic ferrite, retained austenite trapped between the plates of ferrite, thin films as those shown in Figure 1 (c) and (d) and Figure 2 have an average size of 38 and $30 \mathrm{~nm}$ for both steels, Table 2. Consistently distribution of thin film sizes for Steel 2, Figure 4, is narrower than that of Steel 1. Bigger differences arise in terms of the austenite block size and distribution between both microstructures, Table 2 . Steel 1 has revealed and average block size of $\sim 0.8 \mu \mathrm{m}$ and a prominent tail towards higher values, some features as big as those pointed out in Figure $1, \sim 2 \mu \mathrm{m}$, in contrast with Steel 2 where the measured average thickness was $\sim 0.6 \mu \mathrm{m}$ and the distribution narrower, Figure 4 . It has been rationalized that about $15 \%$ of the volume contained within the boundaries of a bainite sheaf consist of retained austenite films interspersed with bainitic ferrite subunits [28]. Hence, the 6 
fraction of the film and blocky type retained austenite can be deduced from the total, see Table 2. In the

present work, retained austenite as thin films is present in both steels almost in the same quantity, $10 \%$, while Steel 1 contains about 10\% more of blocky austenite than Steel 2.

Smaller and narrower distribution of retained austenite in Steel 2 as compared with Steel 1, is coherent the PAGS measurements, $37 \pm 1 \mu \mathrm{m}$ and $20 \pm 1 \mu \mathrm{m}$ for Steel 1 and 2 respectively. In Steel 2, at the austenitisation $\mathrm{T}, \mathrm{V}(\mathrm{CN})$ precipitates are expected to exerted control on the PAGS by pinning of the grain boundaries [20,29], it has to be noted though that such precipitates were not seek or observed in TEM.

Table 3 shows the retained austenite chemical composition derived from the lattice parameter obtained fron X-ray and following the procedure formerly described. Results thus obtained indicate that there are no differences in composition between retained austenite in Steel 1 and Steel 2 other than those inherent to their bulk chemical composition, i.e. $\mathrm{Mn}, \mathrm{Ni}$ and $\mathrm{V}$ content. The $\mathrm{C}$ enrichment of retained austenite is a natural consequence of bainite transformation mechanisms, once bainite stops growing the excess of $\mathrm{C}$ trapped within diffuses to the parent austenite. Moreover, it should be highlighted the fact that X-ray is a "bulk" analysis in the sense that $\mathrm{C}$ content estimation by means of this technique is an average of regions of the material that may contain carbon enriched regions such as dislocations and phase interfaces, which are very distinctive features of this type of microstructures [30]. Therefore this technique is unable to disclose the large variation of austenite $\mathrm{C}$ content from region to region. It has been proved that in bainitic microstructures of the type shown in this work, $\mathrm{C}$ in austenite is distributed inhomogeneously, where thin films of retained austenite trapped between bainite plates can host $\mathrm{C}$ in much higher quantities than the blocks trapped between the sheaves of bainite [18,31-33].

As previously indicated, an indirect measurement of the dislocation density can be derived from microstrain measurement, broadening in the X-ray diffraction peaks. The dislocation density value thus obtained for bainitic ferrite $\left(\rho_{\alpha}\right)$ in both steels is $\sim 1.1 \times 10^{16} \mathrm{~m}^{-2}$. In the case of retained austenite the 7 
measured microstrain differences resulted in dislocation densities, $\rho_{\gamma}$, of $6.9 \times 10^{15}$ and $9.0 \times 10^{15} \mathrm{~m}^{-2}$ for

Steel 1 and 2 respectively. The results are consistent with the formation of a higher fraction of bainitic ferrite in Steel 2 as compared with Steel 1. Note that those dislocation density values are in good agreement with those previously reported for similar microstructures [6,34].

\section{Mechanical behaviour}

Typical strain-stress curves from tensile tests at room temperature are presented in Figure 5. The curves are characterized by continuous yielding, as expected from microstructures containing unlocked dislocations introduced by the plastic accommodation of the shape change. Although there is evidence that ferrite retains an excess concentration of carbon, even after annealing, the majority of dislocations are believed to be mobile. The gradual yielding behaviour sometimes persists after stress-relief heattreatments. There is a variety of obstacles to dislocation motion, (solute atoms, boundaries, thin films of retained austenite), each with a different ability to obstruct plastic deformation. Many of the obstacles are not uniformly distributed so there will exist obstacle-free areas into which dislocations can penetrate at low stresses, thus giving rise to a gradual deviation from elastic deformation. Another scale of heterogeneity can arise when a representative fraction of softer phase is included in the microstructure such as retained austenite. Plastic deformation at first focuses in the softer phase, the hard phase only begins to deform when the softer phase has strain hardened sufficiently to transfer load, leading to a continuous yielding.

Table 4 contains a summary of the mechanical properties obtained for both steels, showing remarkable levels of strength, with yield strengths (YS) ranging from 1.4 to $1.7 \mathrm{GPa}$ and ultimate tensile strengths (UTS) of about 2.1 GPa. Strength can be rationalized if we keep in mind that there are several operative strengthening mechanisms that may contribute to the strength of ferrite; (a) size of the bainitic ferrite plates, the thinner they are the shorter the mean free path for dislocation glide is, leading to the 
enhancement of the strength, (b) dislocation density and (c) carbon in solid solution within ferrite. But, in

this context it has been known, that bainitic ferrite is supersaturated with an excess of carbon [32]. This carbon fails to partition into the residual austenite in spite of the fact that the process is not limited by atomic mobility [35], or even in spite of prolonged heat treatment [31,32,36-38]. An interpretation of these observations partially attributed the reluctance of the carbon to partition on the presence of dislocations which trap the solute. However, recent work has shown conclusively using the atom-probe technique that large quantities of excess carbon may also remain in defect-free solid solution $[39,40]$. Therefore, there may be a contribution of $\mathrm{C}$ in both, solid solution and through its effect on the mobility of dislocations.

Usually the well known Hall-Petch relation is used to describe the microstructure-size contribution to strength of coarse-grained microstructures, since it relies on the existence of sufficient space on a slip plane to build a pile-up of dislocations. In low temperature bainite it has been shown that growth happens in the form of very fine plates. The mean free path through these plates is only about twice the thickness of the plate. Dislocation pile-ups cannot therefore form and the Hall-Petch relation ceases to apply. Instead, yielding involves the spread of dislocations which are present in the plate boundaries, between pinning points until the resulting loop hits the perimeter of the plate. When the energetics of this process are considered [41,42], the grain size strengthening becomes $\Delta \sigma \approx 115 \mathrm{~L}^{-1}$ where $\mathrm{L} \approx 2 \mathrm{t}$ is the mean linear intercept measured in $\mu \mathrm{m}$, and $\Delta \sigma$ in $\mathrm{MPa}$. From dislocation density the contribution is given by $\Delta \sigma \approx$ $7.3410^{-6} \rho^{0.5}$ [43], where $\rho$ is in $\mathrm{m}^{-2}$, and $\Delta \sigma$ in MPa. Keeping in mind that Steel 1 contains less bainitic ferrite that Steel 2, the contribution to the strength of the microstructure arising from the plate thickness is estimated to be 855 and $1100 \mathrm{MPa}$ respectively while from the dislocation density is much lower, i.e. 446 and $515 \mathrm{MPa}$.

So far, all the strength contributions analysed correspond to ferrite, which is the strongest and dominant phase. Therefore, it is difficult to assess the retained austenite contribution to strength in these 9 
microstructures. Qualitatively, retained austenite interlath films can increase the strength by transforming

to martensite during testing by the TRIP effect.

The levels of ductility accompanying such high strength values are quite reasonable, $\varepsilon_{\mathrm{T}}$ of 7.7 and $14 \%$ for Steel 1 and 2 respectively. In this sense, it is evident from Figure 5 and Table 4, that plastic deformation is uniformly distributed along the gauge length of the samples, showing little or no necking, in other words, most or all of the total elongation achieved is uniform elongation. This behaviour is also visible in the incremental work hardening curves, "n" vs. strain in Figure 5, where in the case of Steel 1 there is a continuous increase towards the instability criteria, straight line, which is never reached, all the elongation is uniform. In the case of the Steel 2, after a rapid increase there is a more progressive evolution up to necking. Surprisingly and contrary to the common trend, in Steel 2 it has been possible to get an increase of ductility without sacrificing strength. In this sense, most of the published data on ductility of bainitic steels point out retained austenite as the microstructural feature controlling ductility [7-9]. Not only because austenite, being an fcc structure has a large number of slip planes, i.e. has a higher ductility and strain hardening rate than ferrite (bcc) $[44,45]$, harder phase [46], and it would be expected to enhance ductility as far as austenite is homogeneously distributed between plate boundaries (film austenite), contributing to suppress crack and/or void initiation at the grain boundaries. However, isolated pools of austenite (blocky austenite) would influence unfavorably on both elongation and strength presumably, because of the strain localization in these areas [28]. There is also the possibility to enhance ductility via TRIP effect i.e. strain induced transformation of retained austenite to martensite. The transformation implies a relaxation of the local stress concentration and extra strain hardening by means of the progressive increase in volume fraction of a hard phase and also by additional plastic deformation due to transformation strains.

Mechanical stability of retained austenite, i.e. its ability to transform to martensite under strain, is a concept that has to be handled carefully. In alloys containing austenite of low mechanical stability, the 
strain-induced transformation occurs in early stages of deformation, resulting in little or null benefit of the

strain hardening related to deterring plastic instability or necking in the later stages of deformation. On the other hand, if austenite becomes mechanically more stable and transforms at higher strains, hence the associated strain hardening effectively increases resistance to necking and fracture. However, if austenite is too stable, the presence of large amounts of austenite at necking (instability criterion) does not guarantee effective TRIP effect. So, the strain induced transformation will enhance ductility if retained austenite is moderately stable against straining. There is a correlation between the shape of the incremental work hardening exponent "n" vs. strain curve, Figure 5, and the rate at which retained austenite transforms to martensite [7-9,47], an interpretation of curves in Figure 5 could be as follows: in the case of Steel 1 there is a rapid transformation of austenite into martensite, at early stages, and it is not possible to get full advantage of the augmentation of ductility consequence of the austenite-martensite transformation. But, in the case of Steel 2 the same transformation proceeds progressively until the instability criterion is reached and the increment in strain hardening thus obtained enhances ductility. In a attempt to correlate the TRIP effect evolution with the ductility behavior, interrupted tensile tests were performed at the strain levels indicated by arrows in Figure 5, and then the evolution of retained austenite fraction was analyzed by means of X-ray. Understanding the main parameters that control the austenitemartensite transformation is of considerable importance in order to obtain detailed knowledge of the ductility behavior of these microstructures, i.e. TRIP effect evolution.

Among those parameters controlling mechanical stability, the chemical composition of retained austenite is known to play an important role. Elements as $\mathrm{C}, \mathrm{Mo}, \mathrm{Ni}$ and $\mathrm{Mn}[48,49]$ significantly enhance the austenite mechanical stability, from $\mathrm{C}$ to $\mathrm{Mn}$ the element influence diminishes. The calculated chemical driving force at room temperature for the transformation of austenite into martensite $\Delta G^{\alpha^{\prime} \gamma}$ (i.e. ferrite of the same chemical composition) [20], see Table 3, implies that Steel 1 is slightly more prone for such transformation than Steel 2, in other words, and attending exclusively to the chemical composition, 
retained austenite in Steel 2 is mechanically more stable than that of Steel 1. A more intuitive way of

presenting such results is by means of Sherif et al. model [50], based on a quantitative theory for the strain induced transformation of retained austenite in a class of TRIP-assisted steels The model allow the progress of austenite transformation to be followed as a function of the plastic strain, chemical composition and the temperature at which the deformation is carried out. The effect of the latter two variables is expressed through the chemical driving force for transformation, which has been introduced into a simple equation for strain induced transformation, $\ln V_{\gamma}-\ln V_{\gamma}^{0}=k_{1} \Delta G^{\alpha^{\prime} \gamma} \varepsilon$, where $V_{\gamma}^{0}$ and $V_{\gamma}$ represent the initial austenite fraction and the remaining fraction, after transformation induced plasticity, respectively, $\varepsilon$ is the plastic strain and $\mathrm{k}_{1}$ is a constant. The model can adequately be used for assessing the austenite mechanical stability in a wide range of TRIP-aided steel and its applicability to bainitic steel has been demonstrated, see for example [8,51]. Theoretical calculations of such type are presented in Figure 6, demonstrating that indeed the rate of strain assisted transformation from austenite to martensite is slightly superior in Steel 1 than in Steel 2 despite its higher $V_{\gamma}^{0}$. As the calculations only account for retained austenite chemical composition, through its influence in the value $\Delta G^{\alpha^{\prime} \gamma}$, the described differences can only be justified in terms of the differences in $\mathrm{Ni}$ and $\mathrm{Mn}$ shown in Table 3, and their depicted influence in austenite mechanical stability.

Attending at the experimental results regarding the strain evolution of retained austenite fraction, Figure 7, it is clear that at first in Steel 1, the rate of transformation is superior to that of Steel 2 indeed, but there is a point where TRIP effect does not evolve and almost $70 \%$ of the retained austenite remains in the microstructure just before failure. On the other hand for Steel 2 transformation progresses during deformation up to much higher strain levels and only $25 \%$ of the retained austenite remains. Therefore it is safe to ensure then that chemical composition of retained austenite itself does not explain the ductility behavior. 
Morphology-size-distribution of retained austenite is a trio playing also an important role on its

mechanical stability $[23,52,53,54]$. Particle size of the retained austenite is a crucial stabilization factor, and it has been suggested for that the grain size of austenite should be in the range of $0.01-1 \mu \mathrm{m}$ to ensure TRIP effect [55]. Larger retained austenite is unstable and transform quickly to martensite at small strains. While grains smaller than $0.01 \mu \mathrm{m}$ might be too stable to undergo the strain-induce transformation $[56,57]$, and the reasons are described as follows. It should be kept in mind that smaller grains of austenite are subjected to a high constrain to transformation exerted by the surrounding matrix (plates of bainitic ferrite). Naturally thin films of retained austenite contain lower potential nucleation sites for the transformation of martensite and, as a consequence, require higher driving force for its nucleation. Finally, as already described, there is a strong correlation between the size of the retained austenite and its C content, showing a higher level of $\mathrm{C}$ supersaturation, strong stabilizer element, as its size decreases.

Detailed observation of X-ray profiles at the different strains, as the $(200)_{\gamma}$ in Figure 8 , also reveals that austenite lattice parameter tends to increase as deformation increases, which is linked with the fact that austenite with lower $\mathrm{C}$ content transform first to martensite, mechanically less stable, being the remaining austenite richer in $\mathrm{C}$, therefore having a bigger lattice parameter. The intensity of the austenite peaks also decreases as deformation increases, i.e. austenite transforms to martensite. In the case of Steel 1 shifting of the peak is evident from $\varepsilon=0 \%$ to $3 \%$, as nearly no austenite-martensite transformation takes place from $\varepsilon=3-7 \%$ the peaks are nearly indistinguishable in terms of height (fraction of austenite) and $2 \theta$ position (C content). On the other hand for Steel 2, the evolution of the intensity and position of the peak is quite evident as the strain increases, the fraction of austenite decreases and its $\mathrm{C}$ content increases.

For Steel 1, with more austenite and bigger blocks than Steel 2, Figure 4, up to $\varepsilon=3 \%$ a $10 \%$ of retained austenite transform to martensite and the $\mathrm{C}$ content only changes from 1.01 to $1.17 \mathrm{wt} \%$, a clear indication that there is a representative fraction of low $\mathrm{C}$ austenite blocks (unstable) that might be transforming, as for example those big blocks detailed in Figure 1. Contrary, Steel 2 with less of those big 
blocks and a narrower distribution and smaller average size of the same, at $\varepsilon=3 \%$ only $4 \%$ of retained

austenite transforms, and the $\mathrm{C}$ content increases from 1.07 to $1.25 \mathrm{wt} \%$, evidencing the existence of a small fraction of very poor in $\mathrm{C}$ austenites that transform at the beginning.

This is supported, if we apply a simple level rule, $C_{\gamma}=V_{\gamma f} C_{f}+V_{\gamma b} C_{b}$, where the subscripts $f$ and $b$ stand for thin film and block respectively and $\mathrm{C}$ and $\mathrm{V}$ for the carbon content, just mentioned, and fraction of each morphology, see Table 2 . To simplify the calculation it is reasonable to assume that up to $\varepsilon=3 \%$, only the blocks will transform, the thin films remain stable, and their average $\mathrm{C}$ content $\left(\mathrm{C}_{\mathrm{f}}\right)$ can be fixed in aprox. 7.41 at.\% [18]. Calculations thus performed reveal that although in Steel 1 the blocky austenite seems to be richer than in Steel 2, 0.6 v.s. $0.4 \mathrm{wt} . \%$, the transformation taken place up to $\varepsilon=3 \%$ leaves a $\mathrm{C}_{\mathrm{b}}$ of 0.65 and $0.6 \mathrm{wt} . \%$ in Steel 1 and 2 respectively, which can only be explained by the existence of a small fraction of very low $C_{b}$ in the case of Steel 2 and a representative fraction of not that low in $C_{b}$ austenite blocks in the case of Steel 1.

In this sense, hetereogeneties in the microstructure that lead to effective variations of the austenite stability are known as favorable for spreading the effect of the transformation all along straining and for postponing localization $[2,58,59]$. But it does not seem to be the case in the present study, where Steel 1 with wider distribution of retained austenite reaches a deformation where the transformation austenitemartensite halts. While in Steel 2, with smaller and narrower distribution of austenite, the transformation carries on up to necking.

Distribution of retained austenite is directly linked to the existing amount, as it has been proved that the formation of strain-induced martensite, vital to reach acceptable ductility properties, can only be tolerated if the austenite maintains a uniform and percolated structure through the material $[51,60]$, the latter in the form of films constituting an interconnected network. It has been shown that below $\sim 10 \%$ of retained austenite the interconnection is lost leading to the failure of the tensile specimen. Apparently in Steel 2 total elongation is reached with a fraction of retained austenite that is very close to this percolation 
threshold, 8\%, while in Steel 1 specimen breaks down when austenite is approximately 30\%, well above

the defined threshold.

So far none of the described parameters controlling the stability of retained austenite, chemical composition and morphology-size-distribution, seem to explain why in Steel 1 there is a halt of the transformation while in in Steel 2, with more stable austenite and a less favorable distribution of sizes, the transformation carries on up to necking.

The reason could be find if kept in mind that austenite-martensite transformation takes place when the corresponding chemical free energy change accompanying transformation is equal to or larger than the energy necessary to overcome the resistance to volume deformation, strain energy and the creation of new surfaces which accompany the transformation. The resistance of austenite to plastic deformation is considered to contribute to the magnitude of this nonmechanical free energy term, and can delay or even halt martensitic transformation [61,62]. In similar terms, the matrix might be playing an important role in the stability and efficiency of TRIP effect [58,63-66], a very strong surrounding matrix could also impede the motion of glissile interfaces necessary for the coordinated movement of atoms that accompanies the austenite-martensite transformation. Therefore less transformation is expected when austenite and the surrounding matrix are stronger. In this sense, elements as $\mathrm{Mn}$ and $\mathrm{Ni}$, both present in different quantities in Steel 1 and 2, are known for its strengthening capacity in solid solution, when compared to $\mathrm{Ni}, \mathrm{Mn}$ by far is the element with the strongest influence $[43,67,68]$, both in austenite and ferrite. Bainitic ferrite in Steel 1 is also expected to contain higher C content than Steel 2, C is the strongest solid solution strengthener. For all those reasons it is speculated that the high strength of austenite and the ferritic matrix where is contained, might be the reasons for the complete stabilization of retained austenite after $\varepsilon=3 \%$ in the case of Steel 1. 


\section{CONCLUSIONS}

1

Two nanostructured bainitic microstructures have been investigated in terms of the strength and ductility relationships with the various microstructural features that characterise these microstructures. Strength has been shown to be controlled by the amount and scale of the bainitc ferrite matrix. The study of the ductility invariably is linked to the evolution of the TRIP effect i.e. the mechanical stability of retained austenite.

Retained austenite microstructural parameters, as chemical composition, morphology-size-distribution and strength have been analysed trying to elucidate which was the role that they were playing on controlling its mechanical stability. According to the results the strength of austenite itself might be an important factor limiting or even halting the TRIP effect, dramatically limiting the ductility of the microstructure.

\section{ACKNOWLEDGEMENTS}

The authors acknowledge E. Urones-Garrote from the Centro de Microscopia y Citometria (UCM) for the assistance with the TEM. C. Garcia-Mateo and F.G. Caballero would like to thank Spanish Ministry of Economy and Competitiveness Plan Nacional de I+D+I (2008-2011) for supporting their research under the auspices of the National Project MAT2010-15330. L. Morales-Rivas also acknowledges the same Ministry for financial support in the form of a PhD research grant (FPI). Behzad Avishan acknowledges the Iranian Science Ministry for the provision of a grant for a short-term stay in CENIM.

\section{REFERENCES}


1. Caballero FG, Santofimia MJ, Capdevila C, García-Mateo C, De García Andrés C (2006) Design of

advanced bainitic steels by optimisation of TTT diagrams and T0 curves. ISIJ Int 46 (10):1479-1488.

Garcia-Mateo C, Caballero FG, Sourmail T, Kuntz M, Cornide J, Smanio V, Elvira R (2012) Tensile behaviour of a nanocrystalline bainitic steel containing 3wt\% silicon. Mater Sci Eng A 549:185-192.

Garcia-Mateo C, Caballero FG, Bhadeshia HKDH (2003) Development of Hard Bainite. ISIJ Int 43 (8):1238-1243.

Garcia-Mateo C, Caballero FG (2007) Design of carbide-free low-temperature ultra high strength bainitic steels. Int J Mater Res 98 (2):137-143.

Garcia-Mateo C, Caballero FG, Sourmail T, Smanio V and Garcia de Andres C (2012) Composition Design Of Nanocrystalline Bainitic Steels By Diffusionless Solid Reaction: Theoretical Calculations. Submited to ISIJ Int for its evaluation.

Garcia-Mateo C, Caballero FG (2005) Ultra-high-strength bainitic steels. ISIJ Int 45 (11):1736-1740. .

Garcia-Mateo C, Caballero FG (2005) The role of retained austenite on tensile properties of steels with bainitic microstructures. Mater Trans, JIM 46 (8):1839-1846.

Caballero FG, García-Mateo C, Chao J, Santofimia MJ, Capdevila C, De Andrés CG (2008) Effects of morphology and stability of retained austenite on the ductility of TRIP-aided bainitic steels. ISIJ Int 48 (9):1256-1262.

Garcia-Mateo C, Caballero FG, Chao J, Capdevila C, Garcia De Andres C (2009) Mechanical stability of retained austenite during plastic deformation of super high strength carbide free bainitic steels. J Mater Sci 44 (17):4617-4624.

. Sandvik BPJ, Navalainen HP (1981) Structure-Property Relationships in Commercial Low-Alloy Bainitic-Austenitic Steel with High Strength, Ductility, and Toughness. Met Technol 8 (pt 6):213-220.

. Bhadeshia HKDH (2001) Bainite in Steels. Transformations, Microstructure and Properties. Second edn. Institute of Materials, Minerals and Mining, London. 
12. Bhadeshia HKDH (1982) Thermodynamic analysis of isothermal transformation diagrams. Met Sci Heat

1 Treat $16(3): 159-165$.

2

\$3 3. Garcia-Mateo C, Caballero FG, Bhadeshia HKDH (2003) Acceleration of low-temperature bainite. ISIJ 5 Int 43 (11):1821-1825.

7

\$4. de Andres CG, Bartolome MJ, Capdevila C, Martin DS, Caballero FG, Lopez V (2001) Metallographic 10

257. Dyson DJ, Holmes B (1970) Effect Of Alloying Additions On Lattice Parameter Of Austenite. J Iron 27

3\$9. Williamson GK, Smallman RE (1956) III. Dislocation densities in some annealed and cold-worked 36

400. MTDATA: Phase Diagram Calculation Software, National Physical Laboratory, Teddington, UK, (2004). 41

42
43 . Bhadeshia HKDH, Christian JW (1990) Bainite in steels. Metall Trans A 21 A (4):767-797..

482. Furuhara T, Kawata H, Morito S, Maki T (2006) Crystallography of upper bainite in Fe-Ni-C alloys. 46 
24. Chang LC, Bhadeshia HKDH (1995) Metallographic Observations Of Bainite Transformation

1 Mechanism. Mater Sci Technol 11 (2):105-108.

2

235. Caballero FG, Yen HW, Miller MK, Yang JR, Cornide J, Garcia-Mateo C (2011) Complementary use of 5 transmission electron microscopy and atom probe tomography for the examination of plastic accommodation in nanocrystalline bainitic steels. Acta Mater 59 (15):6117-6123.

390. Caballero FG, Miller MK, Babu SS, Garcia-Mateo C (2007) Atomic scale observations of bainite 31

453. Stone HJ, Peet MJ, Bhadeshia HKDH, Withers PJ, Babu SS, Specht ED (2008) Synchrotron X-ray 46

Cornide J, Garcia-Mateo C, Capdevila C, Caballero FG (2012) An assessment of the contributing factors to the nanoscale structural refinement of advanced bainitic steels. J Alloys Compd. doi:10.1016/j.jallcom.2011.11.066.

. Bhadeshia HKDH, Edmonds DV (1983) Bainite in Silicon Steels: New Composition-Property Approach. Part 1. Met Sci Heat Treat 17 (9):411-419.

Gladman T (1997) The physical metallurgy of microalloyed steels. Institute of Materials, London. transformation in a high carbon high silicon steel. Acta Mater 55 (1):381-390.

Caballero FG, Garcia-Mateo C, Santofimia MJ, Miller MK, García de Andrés C (2009) New experimental evidence on the incomplete transformation phenomenon in steel. Acta Mater 57 (1):8-17.

Bhadeshia HKDH, Waugh AR (1982) Bainite: An atom-probe study of the incomplete reaction phenomenon. Acta Metall 30 (4):775-784.

studies of austenite and bainitic ferrite. Proc R Soc London, Ser A 464 (2092):1009-1027.

Garcia-Mateo C, Caballero FG, Capdevila C, Andres CGd (2009) Estimation of dislocation density in bainitic microstructures using high-resolution dilatometry. Scr Mater 61 (9):855-858.

5. Bhadeshia HKDH (1987) Bainite in Steels. Paper presented at the Phase transformations '87. 
36. Peet M, Babu SS, Miller MK, Bhadeshia H (2004) Three-dimensional atom probe analysis of carbon 1 distribution in low-temperature bainite. Scr Mater 50 (10):1277-1281.

2

37. Garcia-Mateo C, Peet M, Caballero FG, Bhadeshia HKDH (2004) Tempering of hard mixture of bainitic 5 39 ferrite and austenite. Mater Sci Technol 20 (7):814-818.

8. Caballero F, Miller M, Clarke A, Garcia-Mateo C (2010) Examination of carbon partitioning into austenite during tempering of bainite. Scr Mater 63 (4):442-445.

Caballero FG, Miller MK, Garcia-Mateo C, Cornide J, Santofimia MJ (2012) Temperature dependence of carbon supersaturation of ferrite in bainitic steels. Scr Mater 67 (10):846-849.

Caballero FG, Miller MK, Garcia-Mateo C, Cornide J (2012) New experimental evidence of the diffusionless transformation nature of bainite. J Alloys Compd. doi:10.1016/j.jallcom.2012.02.130.

Langford G, Cohen M (1969) Strain Hardening of Iron by Severe Plastic Deformation. ASM-Trans 62:623-638.

. Langford G, Cohen M (1970) Calculation of cell-size strengthening of wire-drawn iron. Metall Mater Trans A 1 (5):1478-1480.

. Bhadeshia HKDH, Honeycombe RWK (2006) Steels: Microstructure And Properties. ButterworthsHeinemann (Elsevier).

. Olofsson J, Larsson D, Svensson IL (2011) Effect of Austempering on Plastic Behavior of Some Austempered Ductile Iron Alloys. Metall Mater Trans A:1-9.

. Yang J, Putatunda SK (2004) Influence of a novel two-step austempering process on the strain-hardening behavior of austempered ductile cast iron (ADI). Mater Sci Eng A 382 (1-2):265-279..

. Lan HF, Liu XH, Du LX (2011) Ultra-hard bainitic steels processed through low temperature heat treatment. Adv Mater Res 156-157:1708-1712.

. Sugimoto K, Kobayashi M, Hashimoto S (1992) Ductility and strain-induced transformation in a highstrength transformation-induced plasticity-aided dual-phase steel. Metall Trans A 23 A (11):3085-3091. 
48. Kirk D, Payne J (1999) Transformation induced in austenitic stainless steels by shot peening. Paper presented at the ICSP7: 7th International Conference on Shot Peening Warsaw (Poland), 29 Sept. 1 October.

9. Nohara K, Ono Y, Ohashi N (1977) Composition And Grain Size Dependence Of Strain Induced 7

Martensitic Transformation In Metastable Austenitic Stainless Steels. Tetsu To Hagane-J ISIJ 63 (5):212222.

12

130. Sherif MY, Garcia-Mateo C, Sourmail T, Bhadeshia HKDH (2004) Stability of retained austenite in 14

26. Zackay VF, Parker ER, Fahr D, Busch R (1967) Enhancement Of Ductility In High-Strength Steels. ASM 27

455. Wang J, Van der Zwaag S (2001) Stabilization mechanisms of retained austenite in transformation46

Sherif MY (2006) Characterisation and Development of Nanostructured, Ultrahigh Strength, and Ductile Bainitic Steels. Ph.D., University of Cambridge, Available online at http://www.msm.cam.ac.uk/phasetrans/2000/phd.html.

Trans 60 (2):252-259.

Sugimoto K-i, Misu M, Kobayashi M, Shirasawa H (1993) Effects of Second Phase Morphology on Retained Austenite Morphology and Tensile Properties in a TRIP- aided Dual-phase Steel Sheet. ISIJ Int 33 (7):775-782.

4. Seol J-B, Raabe D, Choi P-P, Im Y-R, Park C-G (2012) Atomic scale effects of alloying, partitioning, solute drag and austempering on the mechanical properties of high-carbon bainitic-austenitic TRIP steels. Acta Mater 60 (17):6183-6199 induced plasticity steel. Metall Mater Trans A 32 (6):1527-1539.

Lanzillotto CAN, Pickering FB (1982) Structure Property Relationships In Dual-Phase Steels. Met Sci Heat Treat $16(8): 371-382$.

Balliger NK, Gladman T (1981) Work Hardening Of Dual-Phase Steels. Met Sci Heat Treat 15 (3):95108. 
58. Lani F, Furnemont Q, Van Rompaey T, Delannay F, Jacques PJ, Pardoen T (2007) Multiscale mechanics

1 of TRIP-assisted multiphase steels: II. Micromechanical modelling. Acta Mater 55 (11):3695-3705.

2

39. Hase K, Garcia-Mateo C, Bhadeshia HKDH (2006) Bimodal size-distribution of bainite plates. Mater Sci

80. Bhadeshia HKDH (2010) Nanostructured bainite. Proc R Soc London, Ser A 466 (2113):3-18.

1థ1. Nichol TJ, Judd G, Ansell GS (1977) The relationship between austenite strength and the transformation

2. Breinan EM, Ansell GS (1970) The influence of austenite strength upon the austenite-martensite 17 transformation in alloy steels. Metall Trans A 1 (6):1513-1520.

3. Ryu JH, Kim D-I, Kim HS, Bhadeshia HKDH, Suh D-W (2010) Strain partitioning and mechanical stability of retained austenite. Scr Mater 63 (3):297-299.

385. Jacques PJ, Ladrière J, Delannay F (2001) On the influence of interactions between phases on the 31

468. Zajac S, Komenda J, Morris P, Dierickx P, Matera S, Peñalba Diaz F (2005) Quantitative structure46

\section{TABLES AND FIGURES CAPTIONS}


Table 1. Chemical composition, all in wt. $\%$.

Table 2. Quantitative data on microstructure at room temperature after isothermal heat treatment at $200^{\circ} \mathrm{C}$. Where $\alpha$ stands for ferrite and $\gamma$ for retained austenite, the fraction of retained as thin films or blocks was calculated as described in the main text [28].

Table 3. Retained austenite chemical composition in wt. \%, calculated as described in ref. $18 . \Delta \mathrm{G}^{\gamma \alpha^{\prime}}$ represents the chemical free energy change for transformation of austenite to martensite with no change in chemical composition.

Table 4. Tensile test results.

Figure 1. Scanning electron micrographs of the microstructure revealed at room temperature after isothermal heat treatment at $200^{\circ} \mathrm{C}$ for steel 1 (a) and (c), and for Steel 2 (b) and (d).

Figure 2. TEM micrographs of the microstructure revealed at room temperature after isothermal heat treatment at $200^{\circ} \mathrm{C}$ for (a) steel 1 and (b) for Steel 2. Also embedded the SAD pattern.

Figure 3. Distribution of bainitic ferrite plate thicknesses and its corresponding average size.

Figure 4. Distribution and corresponding average sizes of retained austenite films and blocks. 
Figure 5. Engineering and true tensile strain-stress curves of Steel 1 and Steel 2, and the corresponding incremental work hardening exponent, $\mathrm{n}$. Straight line represents the instability criterion, i.e. $\varepsilon_{\mathrm{p}}=\mathrm{n}$. Arrows indicate at which strains the interrupted tensiles tests were performed.

Figure 6. Theoretical evolution of un-transformed retained austenite as a function of strain.

Figure 7. Experimental evolution of transformed retained austenite as a function of strain.

Figure 8. X-ray $(200)_{\gamma}$ peak profile evolution as a function of strain.

\section{TABLES AND FIGURES}

Table 1. Chemical composition, all in wt.\%. 


\begin{tabular}{|l|c|c|c|c|c|c|c|c|c|}
\hline & $\mathrm{C}$ & $\mathrm{Si}$ & $\mathrm{Mn}$ & $\mathrm{Ni}$ & $\mathrm{Mo}$ & $\mathrm{Cr}$ & $\mathrm{V}$ & $\mathrm{Co}$ & $\mathrm{Al}$ \\
\hline Steel 1 & 0.91 & 1.58 & 1.98 & 0.06 & 0.25 & 1.12 & 0 & 1.37 & 0.53 \\
\hline Steel 2 & 0.90 & 1.51 & 0.94 & 2.61 & 0.25 & 1.14 & 0.09 & 1.37 & 0.59 \\
\hline
\end{tabular}

Table 2. Quantitative data on microstructure at room temperature after isothermal heat treatment at $200^{\circ} \mathrm{C}$. Where $\alpha$ stands for ferrite and $\gamma$ for retained austenite, the fraction of retained as thin films or blocks was calculated as described in the main text [28].

\begin{tabular}{|l|c|c|c|c|c|c|c|}
\hline & \multicolumn{2}{|c|}{ Fraction $( \pm 0.03)$} & \multicolumn{2}{c|}{ Fraction of } & \multicolumn{3}{c|}{ Size/nm } \\
\hline & $\alpha$ & $\gamma$ & $\gamma$ films & $\gamma$ blocky & $\alpha$ plates & $\gamma$ films & $\gamma$ blocks \\
\hline Steel 1 & 0.58 & 0.42 & 0.09 & 0.33 & $39 \pm 2$ & $38 \pm 2$ & $808 \pm 22$ \\
\hline Steel 2 & 0.67 & 0.33 & 0.10 & 0.23 & $35 \pm 1$ & $30 \pm 1$ & $598 \pm 23$ \\
\hline
\end{tabular}

Table 3. Retained austenite chemical composition in wt.\%, calculated as described in ref.18. $\Delta \mathrm{G}^{\gamma \alpha^{\prime}}$ represents the chemical free energy change for transformation of austenite to martensite with no change in chemical composition.

\begin{tabular}{|l|c|c|c|c|c|c|c|c|c|c|}
\hline & $\mathrm{C}$ & $\mathrm{Si}$ & $\mathrm{Mn}$ & $\mathrm{Ni}$ & $\mathrm{Mo}$ & $\mathrm{Cr}$ & $\mathrm{V}$ & $\mathrm{Co}$ & $\mathrm{Al}$ & $\Delta \mathrm{G}^{\gamma \alpha^{\prime}} / \mathrm{Jmol}^{-1}$ \\
\hline Steel 1 & 1.01 & 1.58 & 2.02 & 0.05 & 0.24 & 1.12 & 0 & 1.36 & 0.52 & -2629 \\
\hline Steel 2 & 1.07 & 1.50 & 0.93 & 2.60 & 0.24 & 1.14 & 0.08 & 1.36 & 0.58 & -2283 \\
\hline
\end{tabular}

Table 4. Tensile test results.

\begin{tabular}{|l|c|c|c|c|c|}
\hline & YS/MPa & UTS/MPa & $\varepsilon_{\mathrm{u}} / \%$ & $\varepsilon_{\mathrm{T}} / \%$ & HV \\
\hline Steel 1 & $1405 \pm 30$ & $2115 \pm 30$ & $7.7 \pm 2$ & $7.7 \pm 2$ & $530 \pm 10$ \\
\hline Steel 2 & $1730 \pm 40$ & $2182 \pm 50$ & $10.5 \pm 2$ & $14.0 \pm 2$ & $561 \pm 10$ \\
\hline
\end{tabular}



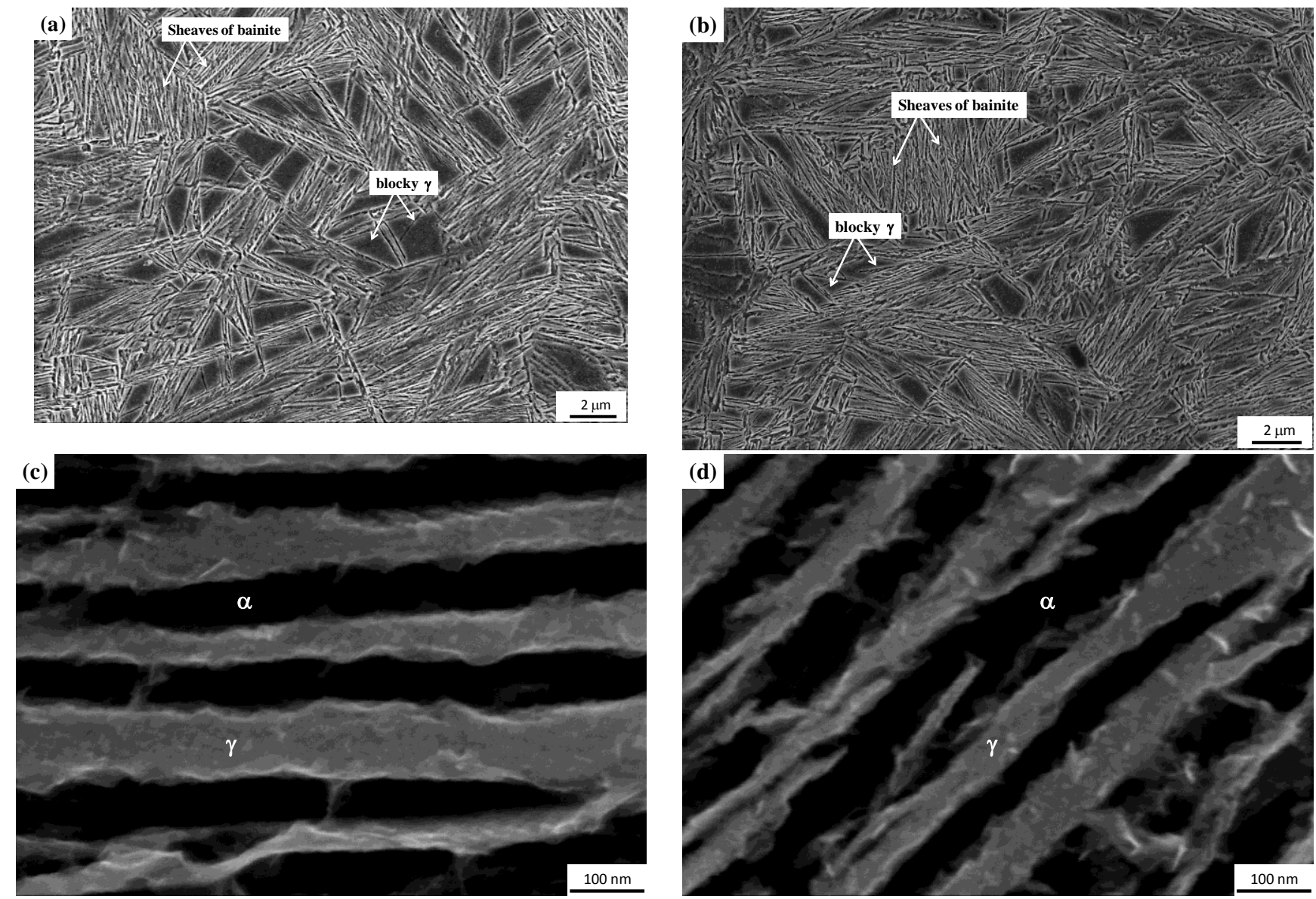

Figure 1. Scanning electron micrographs of the microstructure revealed at room temperature after isothermal heat treatment at $200^{\circ} \mathrm{C}$ for steel 1 (a) and (c), and for Steel 2 (b) and (d). 

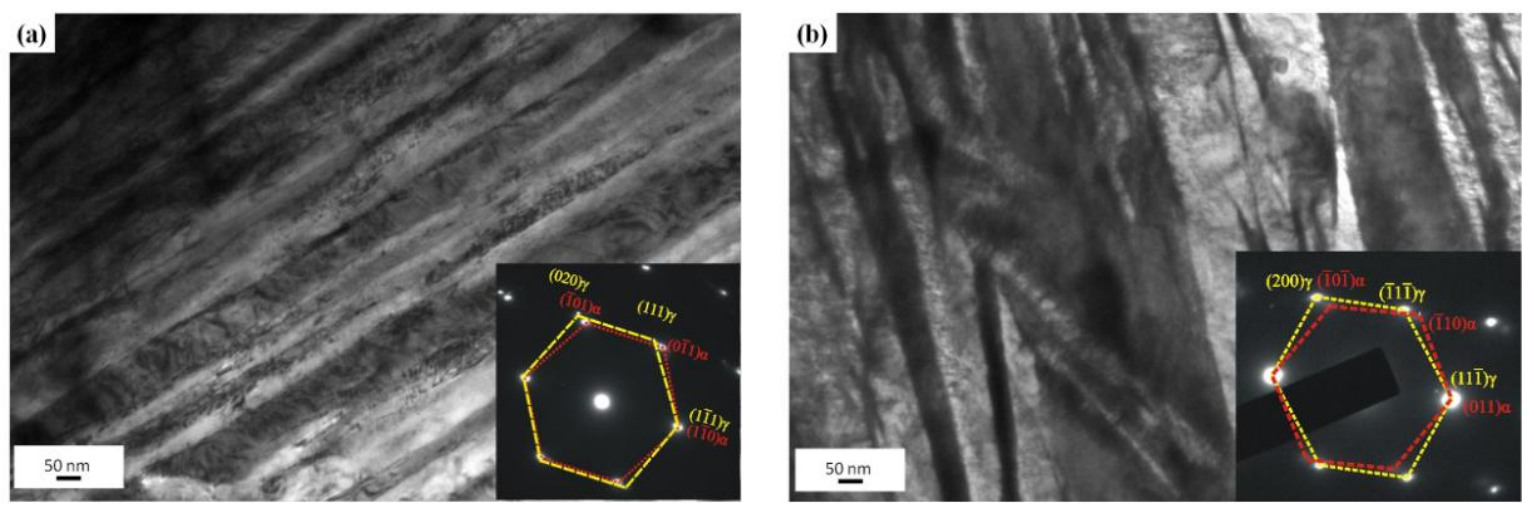

Figure 2. TEM micrographs of the microstructure revealed at room temperature after isothermal heat treatment at $200^{\circ} \mathrm{C}$ for (a) steel 1 and (b) for Steel 2. Also embedded the SAD pattern. 


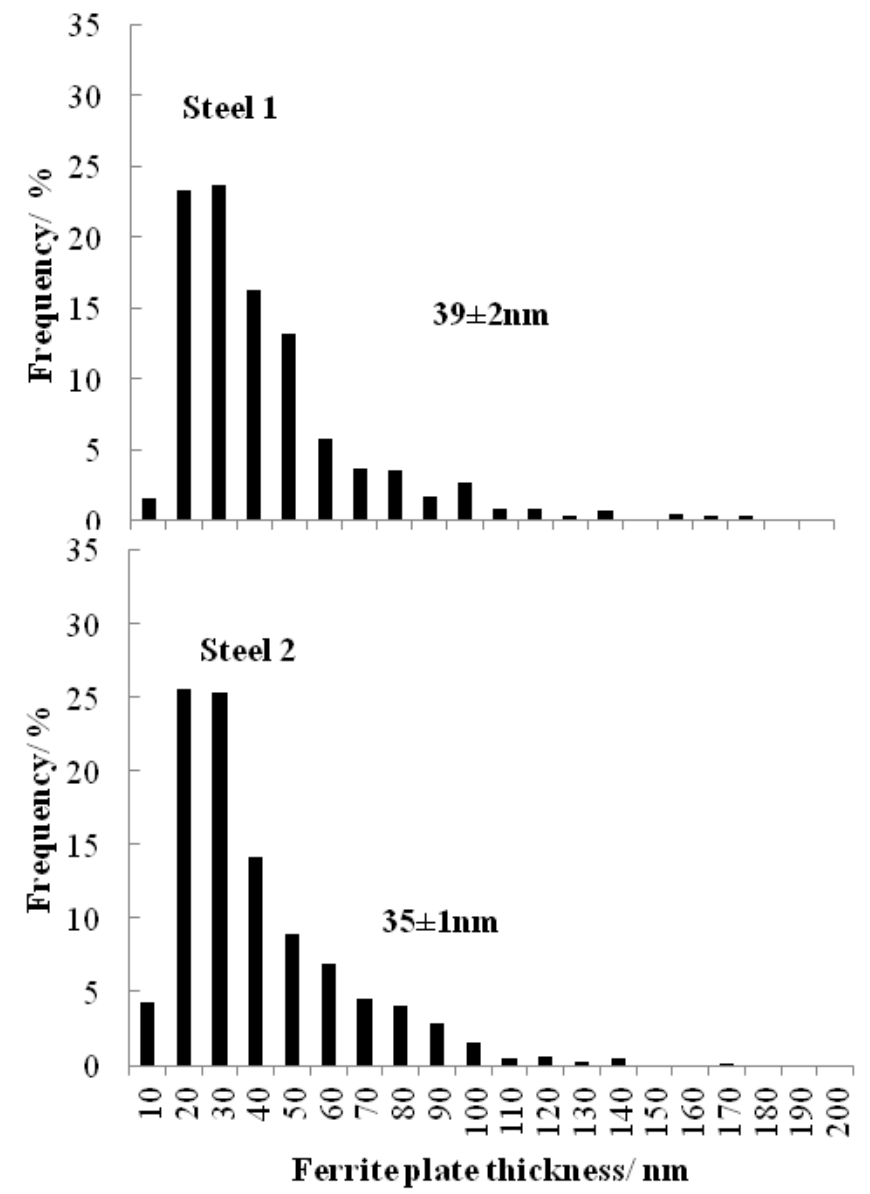

Figure 3. Distribution of bainitic ferrite plate thicknesses and its corresponding average size. 


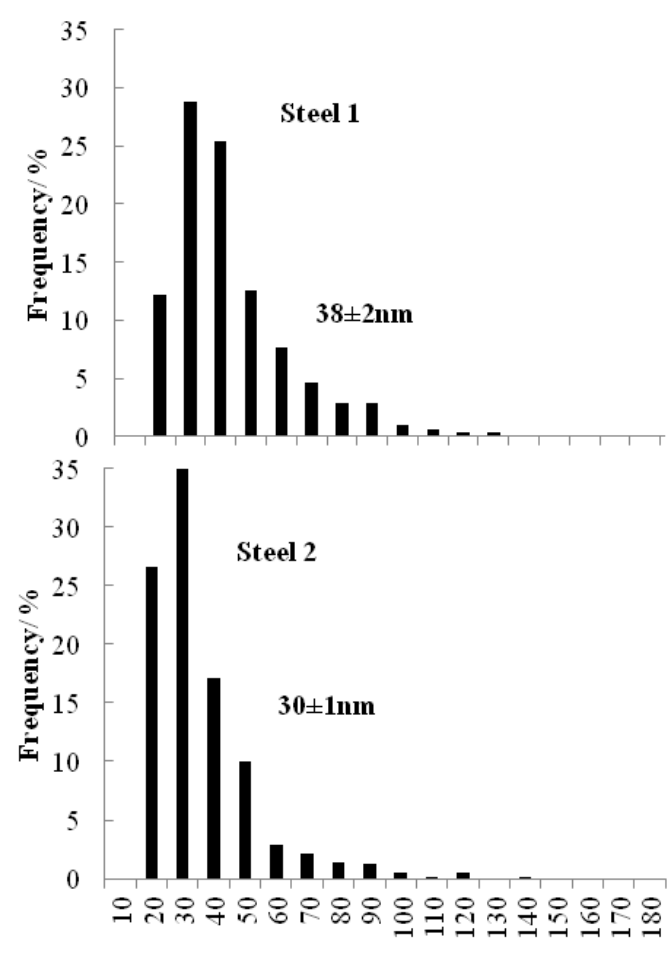

Thin film size/nm

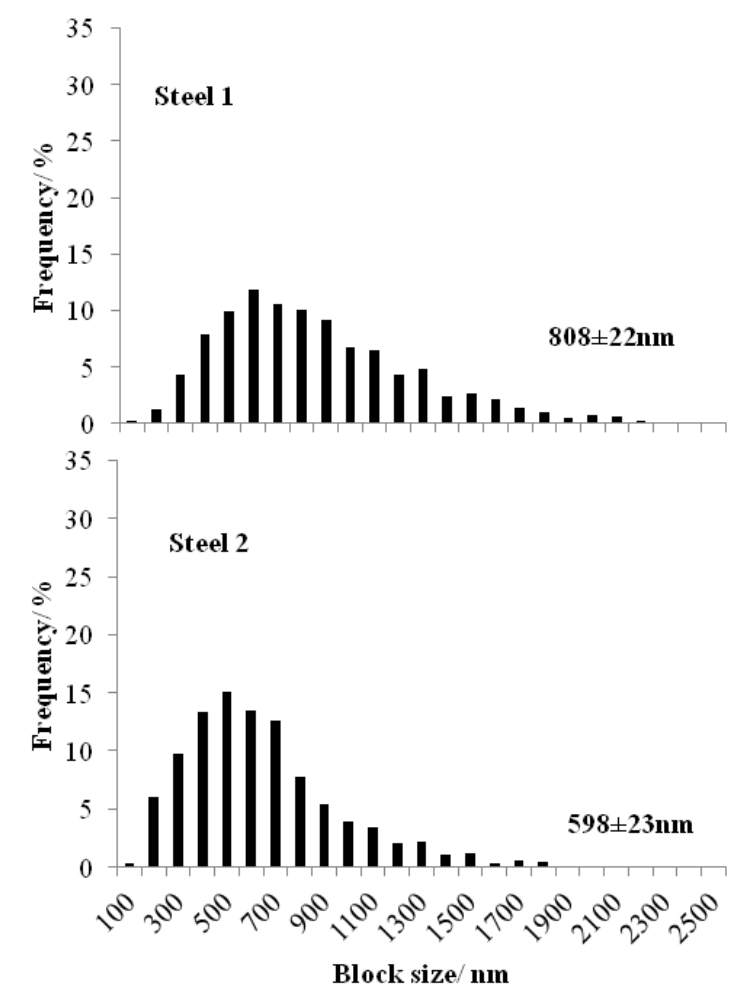

Figure 4. Distribution and corresponding average sizes of retained austenite films and blocks. 

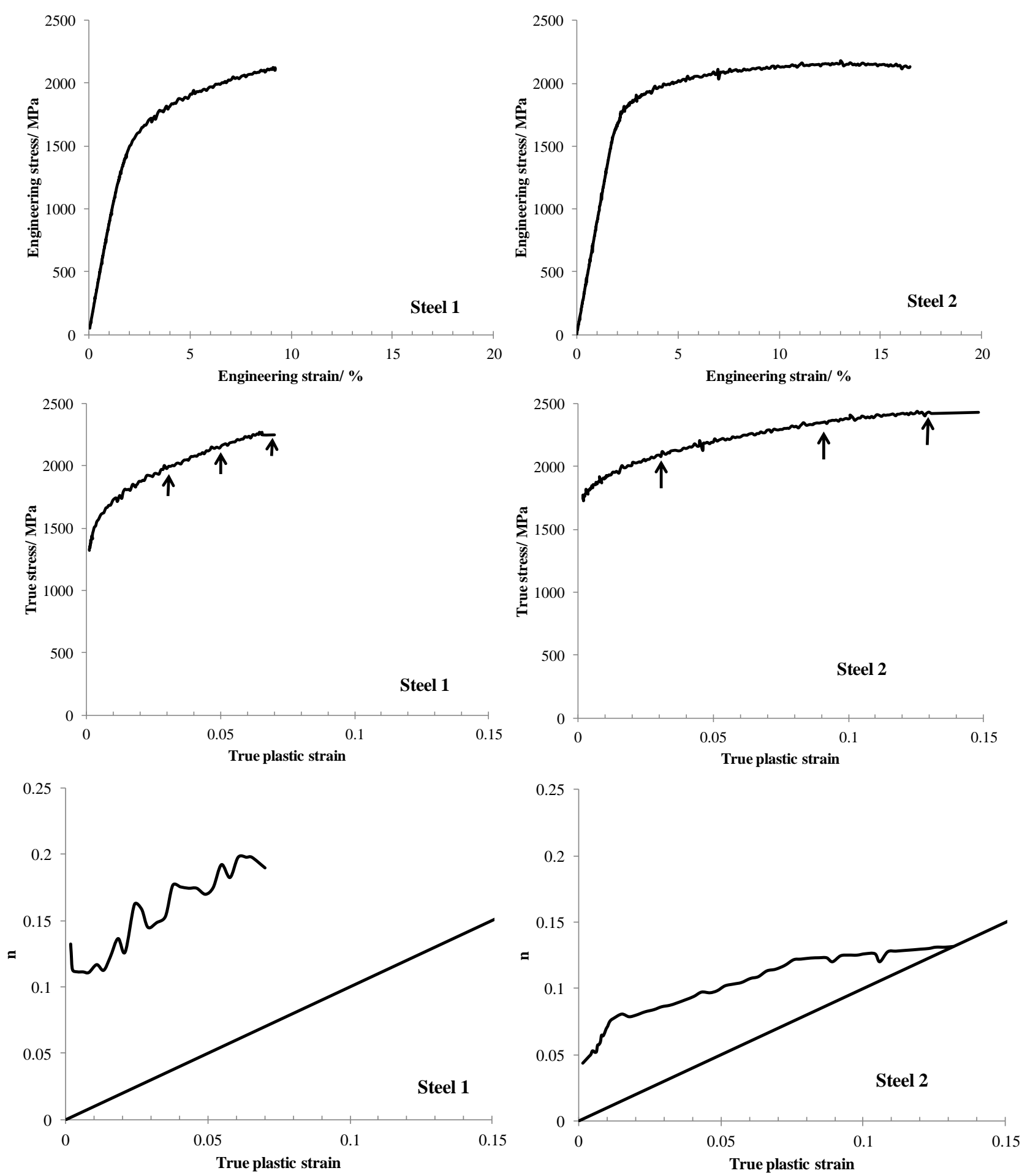

Figure 5. Engineering and true tensile strain-stress curves of Steel 1 and Steel 2, and the corresponding incremental work hardening exponent, n. Straight line represents the instability criterion, i.e. $\varepsilon_{\mathrm{p}}=\mathrm{n}$. Arrows indicate at which strains the interrupted tensile tests were performed. 


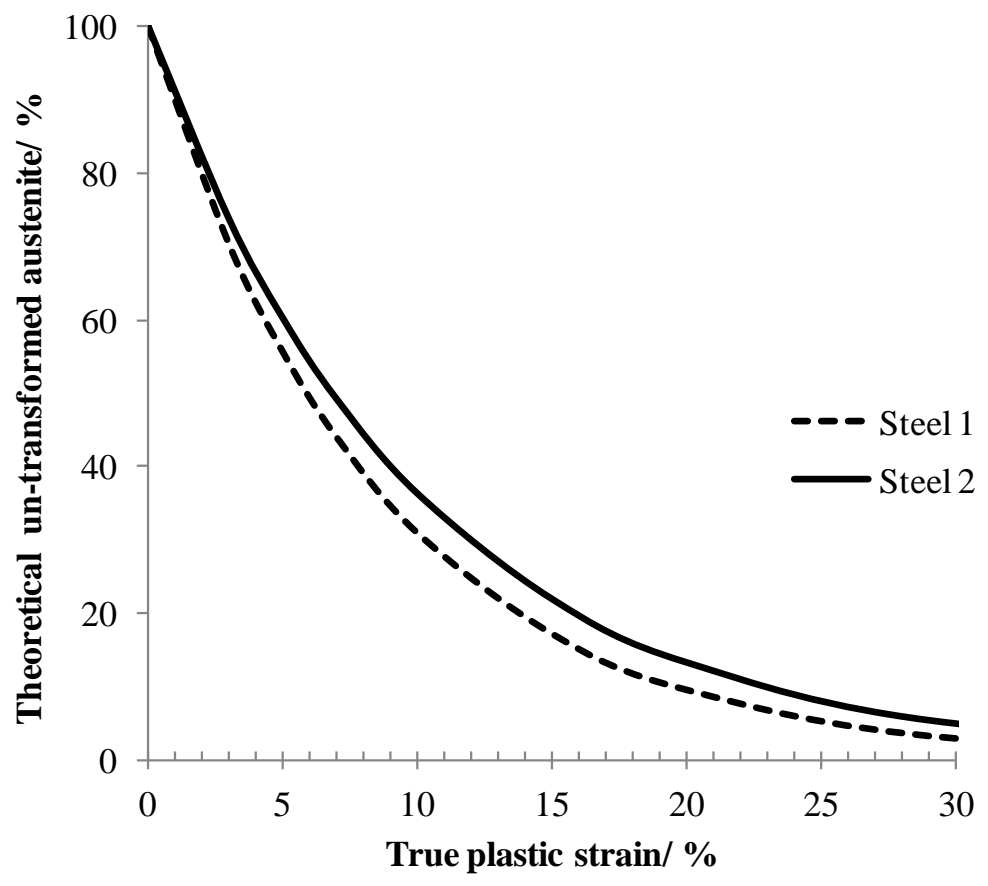

Figure 6. Theoretical evolution of un-transformed retained austenite as a function of strain. 
1

2

3

4

5

6

7

8

9

10

11

12

13

14

15

16

17

18

19

20

21

22

23

24

25

26

27

28

29

30

31

32

33

34

35

36

37

38

39

40

41

42

43

44

45

46

47

48

49

50

51

52

53

54

55

56

57

58

59

60

61

62

63

64

65

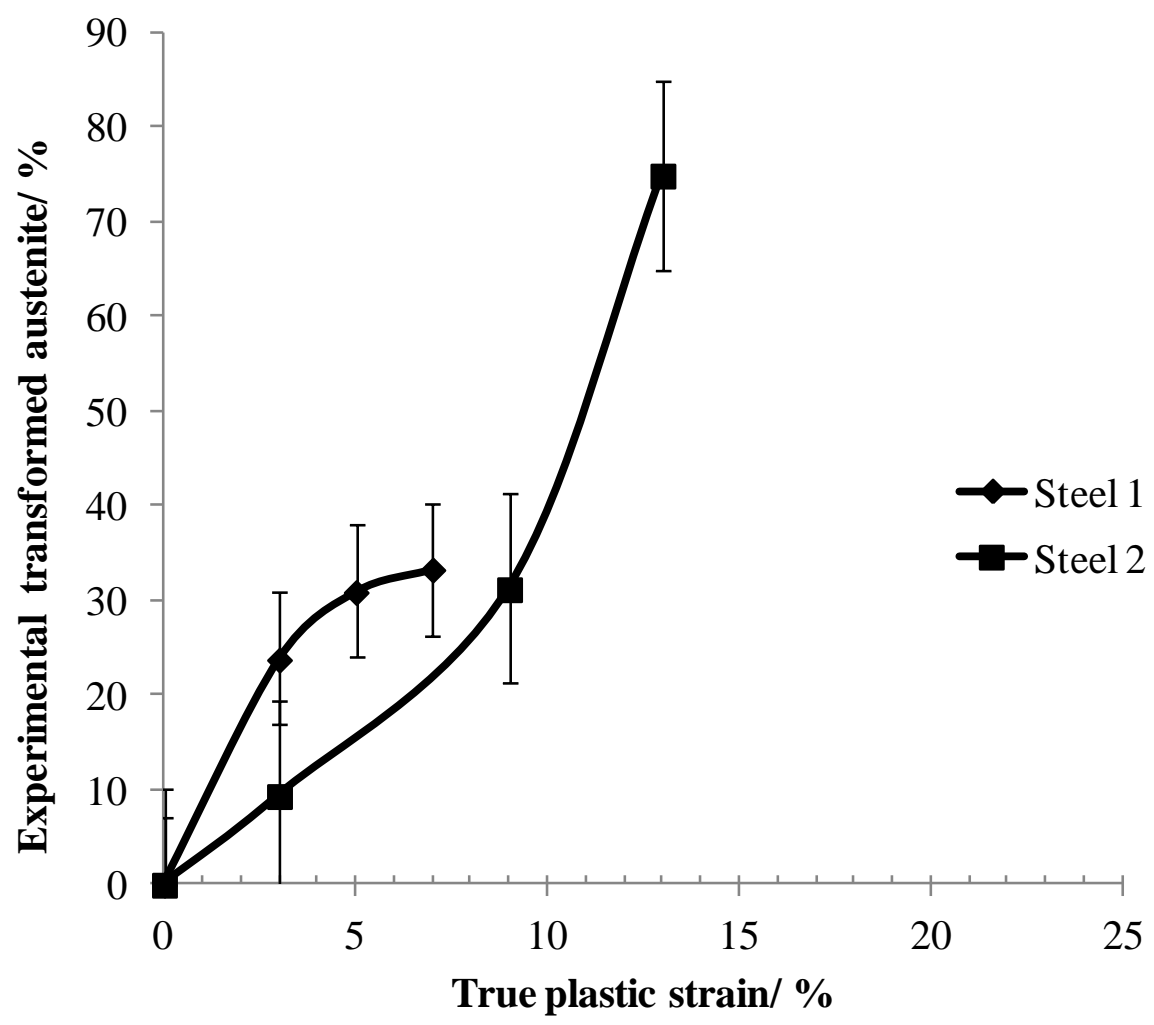

Figure 7. Experimental evolution of transformed retained austenite as a function of strain. 


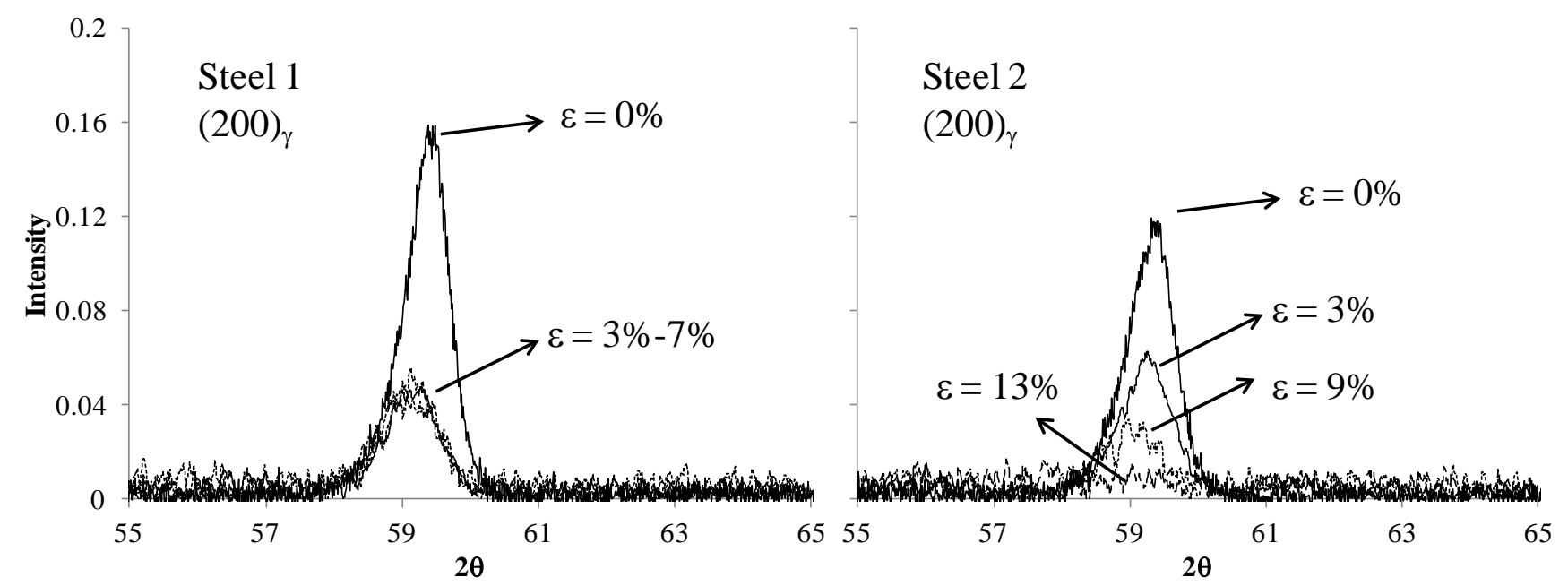

Figure 8. X-ray $(200)_{\gamma}$ peak profile evolution as a function of strain. 